\title{
Monitoring Stations for Surface Water Quality 1
}

\author{
Qingren Wang, Yuncong Li, Thomas Obreza, and Rafael Munoz-Carpena ${ }^{2}$
}

\section{Introduction}

The traditional approach to water quality monitoring involves manually sampling water at remote sites and transporting it to a laboratory for chemical analysis. This approach, while relatively non-technical and easily repeatable, is also:

- time-consuming,

- has a high labor cost,

- may be limited by weather conditions,

- may lead to inconsistent results,

- does not allow for continuous data collection.

New technology and instrumentation have improved our ability to monitor water quality continuously regardless of weather and accessibility. Specialized probes measure water quality parameters, electronic logging devices record and store data, and automatic samplers capture multiple water samples on either time or flow intervals. Telecommunication devices allow data to be downloaded remotely to an office or a laboratory, which makes site monitoring much easier, especially from remote locations.

\section{Building, Using, and Maintaining a State-of-the-Art Water Quality Monitoring Station}

The following approach, instruments and basic knowledge are necessary to build an automatic water sampling station that meets U.S. Environmental Protection Agency (EPA) and Florida Department of Environmental Protection (FDEP) requirements for nutrient sampling in surface water.

\section{SOPs}

Develop standard operating procedures (SOPs) for surface water sampling and chemical analysis according to EPA and FDEP requirements. These SOPs document all required steps for sampling and analysis. They are also useful to train new employees and serve as a reference for regulatory agencies. For detailed information, refer to EPA and FDEP websites:

www.epa.gov/region04/sesd/eisopqam/eisopqam.html and www.floridadep.org/labs/qa/sops.htm

1. This document is Fact Sheet SL218, a publication of the Soil and Water Science Department, Florida Cooperative Extension Service, Institute of Food and Agricultural Sciences, University of Florida. Publication date: September 2004. Visit the EDIS website at http://edis.ifas.ufl.edu.

2. Qingren Wang, Postdoctoral Research Associate, and Yuncong Li, Associate Professor, Tropical Research and Education Center, Homestead, FL 33031, and Department of Soil and Water Science, Institute of Food and Agricultural Sciences, University of Florida, Gainesville, FL 32611; Thomas Obreza, Professor, Department of Soil and Water Science, Institute of Food and Agricultural Sciences, University of Florida, Gainesville, FL 32611; Rafael Munoz-Carpena, Assistant Professor, Tropical Research and Education Center, Homestead, FL 33031, and Department of Agricultural and Biological Engineering, Institute of Food and Agricultural Sciences, University of Florida, Gainesville, FL 32611.

The Institute of Food and Agricultural Sciences (IFAS) is an Equal Employment Opportunity - Affirmative Action Employer authorized to provide research, educational information and other services only to individuals and institutions that function without regard to race, creed, color, religion, age, disability, sex, sexual orientation, marital status, national origin, political opinions or affiliations. For information on obtaining other extension publications, contact your county Cooperative Extension Service office. Florida Cooperative Extension Service / Institute of Food and Agricultural Sciences / University of Florida / Larry R. Arrington, Interim Dean 


\section{Site Selection and Construction}

Site selection depends on the type of water to be monitored. Types of water bodies that may be monitored include (Fig. 1):

- streams;

- ditches that drain farmland;

- conveyance canals.

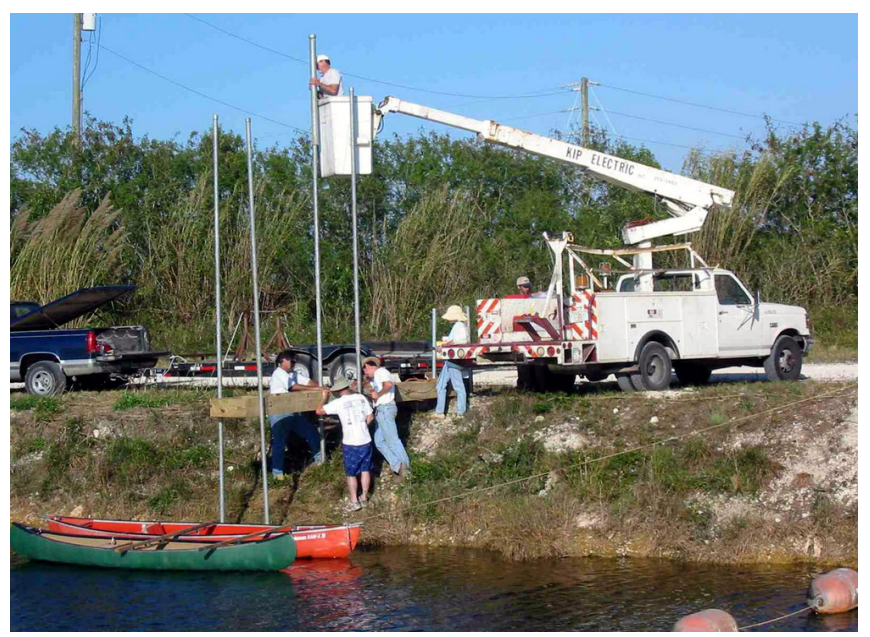

Figure 1. Site selection and construction.

The sample collection location should provide samples that are representative of the water body:

- Water movement should be relatively constant.

- Flow rate or total discharge should be easy to measure.

- The site should be accessible to a field crew with minimal interference.

Once a site has been selected, install the following (Fig. 2):

- A walkway from land to a dock built over the water body that will hold instruments and allow for easy access.

- A metal pole to hold solar panels for power generation and an antenna for telecommunication.

-8- to 10-foot sections of 12-inch PVC pipe, depending on the size of equipment selected, to house water sampling and measuring instruments.

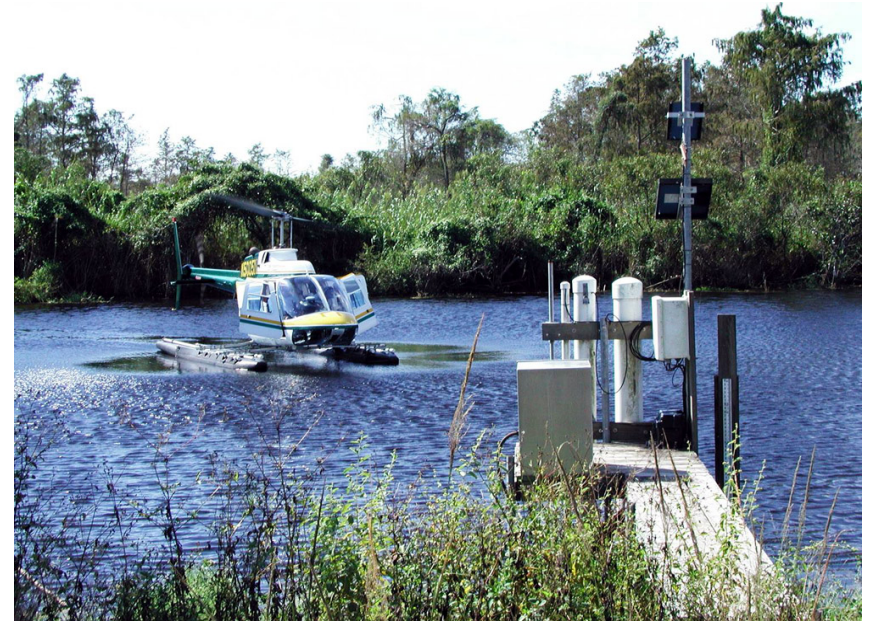

Figure 2. A completed water quality monitoring station.

- A metal cabinet at least 20 inches in width and depth and 35 inches high to house the autosampler.

- A small water-proof cabinet (available from Campbell Scientific Inc., www.campbellsci.com) for the data logger and other devices.

- A flow meter.

- A modem for telecommunication.

Profile measurement:

- The stream or canal "profile" is the cross-sectional area of the water body at the monitoring station. The profile is used in the calculation of total water discharge.

- The profile is measured either manually or with remote detecting equipment (e.g. equipment manufactured by RD Instruments, www.rdinstruments.com). Computer software (such as RDIs Winriver program) can be used to calculate water flow rate or total discharge.

\section{Devices and Instruments}

\section{Power Supply}

Install a solar panel for power generation if standard electrical service is not available.

- A 12-volt DC, 20 watt solar panel is usually enough to supply the power needed by a monitoring station. The panel should be about 6 feet above the dock, facing south at a 45 angle. 
- Install two 12-volt DC rechargeable batteries (Power-Sonic Corporation, www.power-sonic.com) connected in series for power back-up in case the solar panel fails.

If a telecommunication system will be used, install the antenna and an additional solar panel of similar voltage to power it.

- Connect the second solar panel to the batteries for power back-up.

- Solar panels can be purchased from B \& A Electronics (www.ba-electronics.com), or from other similar vendors. Companies that sell solar panels usually provide installation instructions.

Caution: If you are not experienced working with electric power or electrical connections, avoid possible injury by consulting a qualified electrician.

\section{Probes}

Instruments (probes) can measure the following water quality parameters, depending on available sensors:

- Temperature

- Dissolved oxygen (DO)

$\cdot \mathrm{pH}$

- Electrical conductivity (EC)

- Salinity

- Turbidity

- Redox (ORP)

- Ammonium

- Nitrate

- Chloride

Multiple probes are available that measure a variety of the above parameters at the same time. Examples of these include:

- Hydrolab from HACH (www.hach.com) (Fig. $3)$.

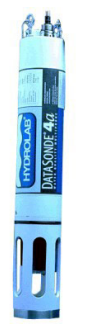

Figure 3. Hach's Hydrolab water quality monitoring probe.

- Multiparameter Monitoring System from YSI Environmental (www.ysi.com/environmental) (Fig. 4).

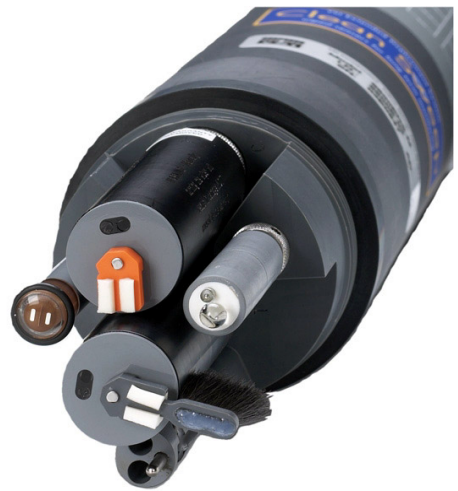

Figure 4. Multiparameter monitoring system from YSI Environmental.

\section{Flow Meter}

Accurate flow measurement is very important when calculating the "load" of an analyte, especially when using flow-proportional sampling.

Install a flow meter under the water surface to measure water velocity. Equipment vendors may provide a representative to install the instrument on site. Examples of flow meters include:

- SonTek (www.sontek.com) (Fig. 5).

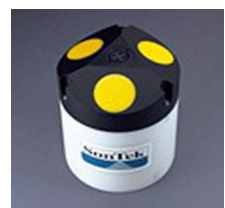

Figure 5. SonTek Flow meter.

- RDI ChannelMaster (Fig. 6).

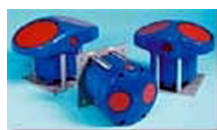

Figure 6. RDI ChannelMaster flow meter 
Install a pressure transducer (e.g. KPSI, www.pressuresystems.com) to calculate the flow or total discharge of water that passes through a specific profile.

Using the measured stream or canal profile, calculate total discharge with an equation that uses the water velocity measured by the flow meter and the water depth measured by the pressure transducer. Some flow meters (e.g. SonTek Argonaut-SL) have a vertical beam that simultaneously measures depth, so a measuring depth separately is not needed.

\section{Autosampler}

Connect the autosampler to the flow meter through a data logger to sample water based on time interval or volume of water discharged (flow-proportional sampling). Examples of autosamplers include:

- ISCO (www.isco.com) (Fig. 7).

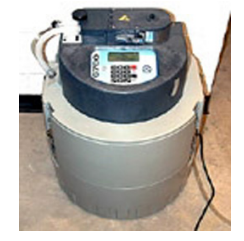

Figure 7. ISCO autosampler.

- American Sigma (www.americansigma.com) (Fig. 8).

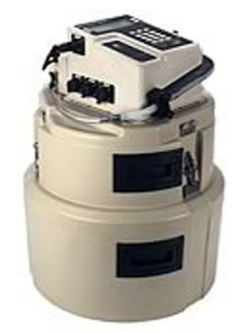

Figure 8. American Sigma autosampler.

Refrigerated autosamplers are available to preserve water samples, but most require $\mathrm{AC}$ power.

In cases where refrigeration is not accessible, pre-acidify containers in the autosampler to preserve samples for about 1 week.

Check EPA/FDEP standard operating procedures to determine if pre-acidification is appropriate for the water quality parameters being measured.
Acidify with nitric or sulfuric acid, depending on the nutrients or metals analyzed:

- Use $\mathrm{H}_{2} \mathrm{SO}_{4}$ for $\mathrm{NO}_{3}+\mathrm{NO}_{2}$ and $\mathrm{NH}_{3}$.

- $\mathrm{HNO}_{3}$ for metals.

- Use $\mathrm{H}_{2} \mathrm{SO}_{4}$ or $\mathrm{HNO}_{3}$ for total P.

\section{Datalogger}

The datalogger is the control center for acquiring, recording, storing, and transferring data, depending on how it is programmed.

Campbell Scientific is a leading manufacturer of dataloggers. Experience is helpful when programming the datalogger, so Campbell Scientific provides training on how to use their instruments.

Datalogger models that can be used in a water quality monitoring station include:

- CR10X (Fig. 9)

- CR510

- CR200

- CR5000

- CR9000

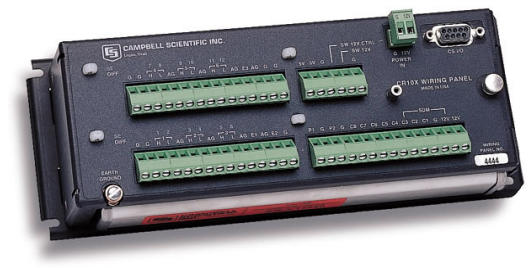

Figure 9. CR10X datalogger.

\section{Setting Up and Programming}

After all sensors and transducers have been calibrated and installed:

- Connect the terminals to the datalogger and the main power supply (refers to datalogger or instrument manual for connection scheme).

- Use a computer and LoggerNet software that can be obtained from Campbell Scientific to program the datalogger. 
- Make sure that all sensors work properly and communicate with the data logger.

Set up a sampling criterion based on time interval or discharge to trigger the autosampler to collect samples, and program the sensing instruments so that they are all synchronized.

Download data to a laptop computer on site, or use the remote telecommunication system to download to a computer at another location.

Dataloggers have a relatively large but limited memory. For example, the CR10X has $128 \mathrm{~K}$ of SRAM, which can store 62,280 data points. Therefore, if an hourly output to final storage includes array ID, year, day, hour, temperature, $\mathrm{pH}$, $\mathrm{EC}$, and DO, eight data points per hour will be sent to memory. Dividing capacity by data points:

62,280 data points $/ 8$ data points per hour $=$ 7,785 hours $=324$ days.

Never wait this long to download data. It is highly recommended to retrieve data on a monthly basis.

\section{Telecommunication}

Several options are available for the telecommunication system, depending on the distance to the site, the ability to reach the site with either radio or hardwire-based signals, and budget options include:

- Land-based telephone line

- Cellular telephone

- Radio communication

- Satellite communication

- Ethernet-TCP/IP connection.

Each of these options can be purchased from Campbell Scientific.

With a remote telecommunication system, a real-time monitoring and control (RTMC) approach can be used to monitor instruments, collect data, and operate the entire system from a distant office or laboratory.

\section{Sample Collection and Analysis}

Place water samples retrieved from the autosampler into a water-proof insulated container filled with ice to keep them cool.

Transport samples to the laboratory as soon as possible after retrieving them.

Store samples in the laboratory at $4^{\circ} \mathrm{C}\left(39^{\circ} \mathrm{F}\right)$ before chemical analysis for nutrients.

Analyze water samples before the maximum storage time specified by the standard analysis procedure has elapsed, e.g. 48 hours for ortho-P (not acidified) and 28 days for total-P (acidified).

Use EPA-approved methods and instruments for analysis:

- Inductively coupled plasma (ICP) spectroscopy or atomic absorption (AA) spectroscopy for metals.

- Gas chromatography (GC) or high-pressure liquid chromatography (HPLC) for organic compounds.

- Auto-analyzer or spectrophotometer for nutrients, $\mathrm{NH}_{4}^{+}, \mathrm{NO}_{3}^{-}, \mathrm{P}$, etc.

Although some water quality parameters can be measured on site, have inorganic compounds like ammonium, nitrate, phosphorus, and chloride analyzed in a qualified laboratory to assure accurate determination.

\section{Site Visits and Maintenance}

Regularly visit water sampling sites to:

- Check for damage to sensors, the data logger, the sample holder, and the power system.

- Remove aquatic weed growth that may be interfering with water sample collection.

If the autosampler is loaded with pre-acidified containers, collect the water samples at least once per week. 
Perform routine maintenance on field instruments and autosamplers following manufacturers instructions:

- Inspect connectors, tubing, and cables. Replace if necessary (Fig. 10).

- Clean multiple probe sensors.

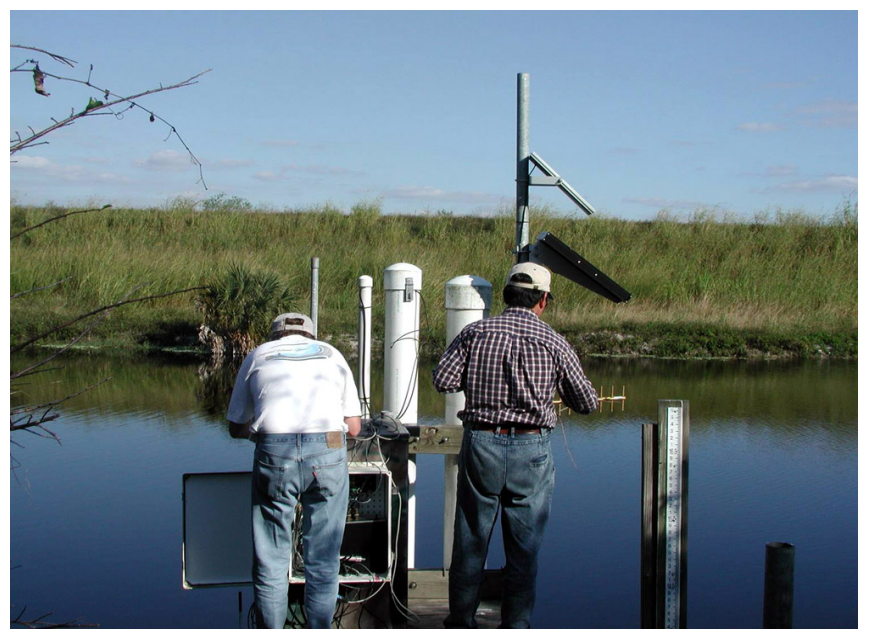

Figure 10. Site visit and routine maintenance.

\section{Summary}

- Develop SOPs for water sampling and analysis to meet EPA and FDEP requirements.

- Select a water sampling site that will allow collection of representative water samples.

- Build a walkway and dock, and install cabinets and PVC pipe to house the instruments.

- Choose appropriate, high-quality equipment and instruments for measurement, monitoring and sampling.

- Set up devices and programs for water monitoring and sampling according to the manufacturers instructions.

- Strictly follow the established SOPs to collect water samples and flow data.

- Visit and maintain the sites regularly. 